\title{
INCLUSÃO NO ENSINO SUPERIOR PELA LENTE OMNILÉTICA: UM FOCO NA FORMAÇÃO DOCENTE
}

\author{
INCLUSIÓN EN LA EDUCACIÓN SUPERIOR POR LA LENTE \\ OMNILECTICA: UN FOCO EN LA FORMACIÓN DE MAESTROS \\ INCLUSION IN HIGHER EDUCATION THROUGH THE \\ OMNILECTICAL LENS: KEEPING AN EYE ON THE TECAHER INITIAL \\ EDUCATION
}

\author{
Mônica Pereira dos SANTOS ${ }^{1}$ \\ Carolina Barreiros de LIMA $^{2}$ \\ Maicon Salvino Nunes de ALMEIDA ${ }^{3}$
}

RESUMO: O presente artigo tem por objetivo discutir omnileticamente a temática da formação de docentes do ensino superior para a promoção da inclusão de pessoas com deficiência na educação superior, tendo em vista, particularmente, os 10 anos de existência da Política Nacional de Educação Especial na Perspectiva da Educação Inclusiva (PNEEPEI) e a situação do alunado com deficiência no ensino superior tomando por base o caso da Universidade Federal do Rio de Janeiro. Pretendemos discutir que impactos ou inspirações a PNEEPEI pode ter causado no sentido de influenciar o movimento de inclusão de estudantes com deficiência na referida universidade e a consequente implicação disso à formação docente.

PALAVRAS-CHAVE: Inclusão em educação. Perspectiva omnilética. Ensino superior. Formação docente.

RESUMEN: El objetivo de este artículo es discutir omnileticamente el tema de la formación de los docentes en la educación superior para promover la inclusión de las personas con discapacidad en la educación superior, especialmente en vista de los 10 años de la existencia de la política nacional de la educación especial en la perspectiva de la educación inclusiva (PNEEPEI) y la situación del estudiante con discapacidades en la educación superior. Tenemos la intención de discutir qué impactos o

1 Universidade Federal do Rio de Janeiro (UFRJ), Rio de Janeiro - RJ - Brasil. Professora Associada do Departamento de Fundamentos da Educação/Faculdade de Educação. ORCID <https://orcid.org/0000-0002-7057-7804>. E-mail: monicapes@gmail.com

2 Universidade Federal do Rio de Janeiro (UFRJ), Rio de Janeiro - RJ - Brasil. Mestranda do Programa de Pós Graduação da Universidade Federal do Rio de Janeiro. ORCID: $\quad<$ http://orcid.org/0000-0001-7572-6859>. E-mail: carol.barreiros.lima@gmail.com

${ }^{3}$ Universidade Federal do Rio de Janeiro (UFRJ), Rio de Janeiro - RJ - Brasil. Mestrando do Programa de Pós-Graduação da Universidade Federal do Rio de Janeiro. ORCID < https://orcid.org/0000-0002-1699-9483 >. E-mail: maiconsalvino@ gmail.com 
inspiraciones la PNEEPEI puede haber causado para influir en el movimiento de inclusión de los estudiantes con discapacidades en la educación superior, teniendo por base la Universidad Federal de Rio de Janeiro y la consiguiente implicación de esta ley a la formación del profesorado.

PALABRAS CLAVE: Inclusión en la educación. Perspectiva omnilectica. Enseñanza superior. Formación de maestros.

ABSTRACT: The current paper aims to carry out an omnilectical analysis about the Education of teachers towards the inclusion of disabled students in higher education. The discussion will be based especially on the Brazilian's 2008 National Policy of Special Education in the Perspective of Inclusive Education and its possible impacts on the inclusion of disabled students in the largest State University of Brazil, the Federal University of Rio de Janeiro, and its implications for university teachers' practices and education.

KEYWORDS: Inclusion in education. Omnilectical perspective. Higher education. Teacher education.

\section{Introdução}

Em 2018, a Política Nacional de Educação Especial na Perspectiva da Educação Inclusiva - PNEEPEI (BRASIL, 2008) completa 10 anos de existência. Trata-se de importante marco de organização da educação especial, em particular porque a vincula à Convenção Internacional sobre os Direitos das Pessoas com Deficiência (2007) e à temática dos Direitos Humanos, além de fundamentar-se em importantes prerrogativas legais de cunho mais inclusivo, instituídas ao longo da história brasileira da educação especial (BRASIL, 2002; 2006; 2007; 2008; 2009ª; 2009b; 2016; 2018).

Provavelmente não por acaso, no início de 2018 o Ministério da Educação anunciou que estaria revisando/atualizando a PNEEPEI. No atual momento (setembro de 2018) o documento está em fase de consulta pública, segundo o próprio MEC. Vale destacar que este processo não tem sido harmonioso, pois tendo em vista as alterações preliminares já apresentadas, a comunidade acadêmica se dividiu, principalmente, entre aqueles que defendem a mudança e os que não. Uma destas alterações tem a ver com a ampliação do público alvo da educação especial para incorporar os transtornos mentais, por exemplo. Outra relaciona-se à defesa da existência de classes e escolas especiais.

No que concerne ao presente artigo, dado que seu foco está no ensino superior, determos nossa atenção nos efeitos desta política quanto à população com deficiência no ambiente da Universidade Federal do Rio de Janeiro. Neste sentido, traremos à luz uma 
importante Lei, a 13.409 de 28 de dezembro de 2016, que modifica a Lei 12.711 de 29 de agosto de 2012 (conhecida como Lei de Cotas) para inserir, entre o público cotista, as pessoas com deficiência. Se é verdade, por um lado, que o texto da referida Lei não menciona a PNEEPEI, não se pode dizer, por outro lado, que não houve influência desta sobre os rumos concernentes à reserva de vagas para pessoas com deficiência no ensino superior, tendo em vista que em alguns dos trechos da PNEEPEI há referências à universidade, como se verá adiante.

Considerando, então, o aniversário de 10 anos da PNEEPEI e os movimentos em torno de sua revisão, assim como a legislação que se segue posteriormente, relativa ao ensino superior, pensamos que seria relevante escrevermos um artigo que se dedicasse a uma análise destes 10 anos no que diz respeito à formação docente para a acessibilidade e o papel das universidades. Que impactos podemos dizer que esta política trouxe ao cotidiano universitário? Que desafios decorreram desta política? O que foi implementado e o que não foi?

Quando falamos em análise, referimo-nos a ter como base nossa perspectiva analítica, que intitulamos de Omnilética. Esta palavra tem origem etimológica grecolatina e foi criada em 2011 (SANTOS, 2013) para significar uma espécie de olhar, ou "lente", por meio da qual podemos enxergar totalidades (eventos/fenômenos sociais, grupais ou pessoais) em um "jogo", ou entrelace, cultural, prático, político, complexo e dialético ao mesmo tempo e em base contínua, como se verá mais adiante.

Desta forma, este artigo se dividirá em 03 partes além desta introdução. A próxima seção tratará de um alinhavo dos principais aspectos da PNEEPEI relacionados ao ensino superior. Em seguida trataremos de como tem sido o acesso e a permanência de estudantes com deficiência desde 2017 na Universidade Federal do Rio de Janeiro (UFRJ), quando da promulgação da Lei 13.409/2016, destacando os principais avanços e desafios da instituição. Neste momento é que procederemos à análise omnilética, recuperando pontos destacados sobre a PNEEPEI e sobre a Lei 13.409. Por fim, procederemos às nossas considerações finais.

\section{A PNEEPEI e o Ensino Superior}

Existem 7 momentos em que as 15 páginas da PNEEPEI se remetem ao ensino superior. A primeira menção está posta ainda na Parte II do documento, intitulada "Marcos históricos e normativos", quando o texto menciona a Resolução CNE/CEP n ${ }^{\circ}$ 
1/2002, que estabelece as Diretrizes Curriculares Nacionais para a Formação de Professores da Educação Básica. Segundo a PNEEPEI, esta Resolução prevê que o ensino superior deve contemplar, "em sua organização curricular, formação docente voltada para a atenção à diversidade e que contemple conhecimentos sobre as especificidades dos alunos com necessidades educacionais especiais” (BRASIL, 2008).

Cabe refletirmos: de que forma as universidades vêm se organizando para atender a esta premissa? E mais: se muitas universidades, a partir da Lei 13.409/16, têm reclamado que não estão preparadas para fornecer tal preparo, alegando que seus docentes, eles mesmos, não tiveram formação para isso, como romperemos este círculo de não formação? Quem precisará tomar a iniciativa? Em nosso ver, cabe às universidades esta iniciativa, e somente a elas. É mais do que necessário que preencham, por meio de variadas formas de formação (continuada e complementar), esta lacuna em sua própria competência para que responda aos anseios da sociedade.

O segundo momento, ainda nesta mesma seção, é quando a PNEEPEI menciona o Plano Nacional de Educação em Direitos Humanos de 2006, que, entre outras coisas, objetivou "desenvolver ações afirmativas que possibilitem acesso e permanência na educação superior" (idem). Ressalta-se que no atual Programa Nacional de Direitos Humanos (PNDH3), de 2009, esta ideia permanece, ainda que não mencione pessoas com deficiência. Atribuímos esta omissão ao fato de o Programa ser anterior à Lei 13.409, que é de 2016.

O terceiro momento refere-se a quando a PNEEPEI invoca o Plano de Desenvolvimento da Educação (2007) e seu eixo de ação voltado para a "permanência das pessoas com deficiência na educação superior". Cumpre dizer que o texto não deixa claros os detalhes de se mencionar este eixo do PNE, mas pela leitura de toda a PNEEPEI fica nítida a preocupação em se pensar a educação especial para além do acesso à educação básica à época, algo que consideramos de suma importância.

A menção seguinte ao ensino superior ocorre na Seção III da PNEEPEI, intitulada "Diagnóstico da Educação Especial" e refere-se às estatísticas de crescimento no número de alunos entre 2003 e 2005, que, segundo o Censo da Educação Especial no Ensino Superior, aumentou $136 \%$ (de 5.078 para 11.999 alunos). Vale lembrar que, segundo o Censo da Educação Superior de 2015 (BRASIL, 2018), entre 2004 e 2014 o aumento foi muito maior: 618,66\%, (de 5.395 para 33.377). Isto, além de reforçar a relevância desta temática e de a problematizarmos, nos remete, minimamente, a pensar 
como os docentes da educação superior estão (e se estão), se preparando para este crescimento, e como vêm reagindo.

A quinta menção aparece na seção dedicada ao objetivo da PNEEPEI (“o acesso, à participação e à aprendizagem dos alunos com deficiência, transtornos globais do desenvolvimento e altas habilidades/superdotação nas escolas regulares"), que, segundo planejado, deveria garantir a "transversalidade da educação especial desde a educação infantil até a educação superior".

Uma vez mais observamos a importância do que a PNEEPEI traz à tona como tarefas de nossa sociedade relativas à garantia de acesso de alunos com deficiências à educação superior, acesso este que precisa ser pensado já desde suas bases, ou seja, da educação básica.

A penúltima menção ao ensino superior da PNEEPEI está na seção das Diretrizes propriamente ditas da política (seção VI), quando reza:

$\mathrm{Na}$ educação superior, a educação especial se efetiva por meio de ações que promovam o acesso, a permanência e a participação dos alunos. Estas ações envolvem o planejamento e a organização de recursos e serviços para a promoção da acessibilidade arquitetônica, nas comunicações, nos sistemas de informação, nos materiais didáticos e pedagógicos, que devem ser disponibilizados nos processos seletivos e no desenvolvimento de todas as atividades que envolvam o ensino, a pesquisa e a extensão (BRASIL, 2008).

Cabe, aqui, pensarmos: isto tem sido feito nas universidades? de que forma? o que tem sido feito tem sido suficiente para atender às demandas oriundas de um crescimento com o percentual que ultrapassa os $600 \%$, como mencionado em parágrafo anterior?

Nesta mesma seção ocorre a última referência ao ensino superior, ao dizer que a formação inicial e continuada deverá capacitar os professores para a docência com conhecimentos específicos da área (de educação especial), o que, por sua vez, lhes permitiria atuar nos Núcleos de Acessibilidade das Instituições de Ensino Superior.

Neste sentido, problematizamos: o que as universidades têm feito desde então para garantir que esta formação aconteça? Que iniciativas têm sido tomadas e qual sua eficácia? É certo que foge de nosso escopo respondermos a todos os questionamentos aqui colocados, posto que estamos pensando a partir de um caso específico, o da UFRJ. Mesmo assim, consideramos importante deixá-los demarcados, em apoio e consonância 
com colegas que vêm pesquisando esta temática (CABRAL, 2017; SIQUEIRA; SANTANA, 2010; SANTANA et al, 2015).

Passaremos, a seguir, para o terceiro momento deste artigo, em que cruzaremos os aspectos levantados anteriormente sobre a formação docente quando da apresentação da PNEEPEI na seção anterior, com o que vem ocorrendo na UFRJ, especialmente após a promulgação da Lei 13.409/16.

\section{A PNEEPEI, a Lei 13.409/16 e seus impactos na UFRJ pela lente omnilética}

Antes de iniciarmos esta seção, faremos uma breve explicação sobre a perspectiva Omnilética de análise. Como explicado acima, trata-se de uma perspectiva analítica que funciona como uma 'lente' por meio da qual procedemos às tentativas de analisar uma totalidade de aspectos em cada fenômeno observado, aspectos esses, em si mesmos, também considerados totalidades.

A perspectiva Omnilética não se configura como uma teoria, na medida em que não pretende explicar as coisas com um 'tom' finalístico de análise, ou seja, não pretende chegar a generalizações, tampouco a conclusões fechadas. Ao contrário, tratase de um olhar múltiplo em constante movimento e em direções plurais sobre os fenômenos. Se há algo de 'finito', ou 'estruturante', nesta perspectiva, é sua única premissa: a de que somos e existimos de forma, ao mesmo tempo, cultural, política, prática, dialética e complexa.

Quando nos referimos à dimensão cultural de sermos humanos e socialmente organizados, queremos dizer que somos imbuídos de valores que nos perpassam de forma tal que muitas vezes nem os percebemos. E que tais valores fundamentam e justificam nossas formas de existir e de nos organizarmos no mundo. São crenças construídas ao longo de nossas vidas (e obviamente, não genéticas), que ficam arraigadas e que são passíveis de alteração quando delas nos damos conta. As culturas influenciam, dialética e complexamente, as práticas e as políticas.

Ao falarmos em práticas, nos referimos aos nossos atos, às nossas ações, conscientes ou não. Tudo na vida é prática, inclusive nada fazer. Todos os verbos são prática: dormir, pensar, comer, estudar, ler, viajar, imaginar, etc. As práticas influenciam, dialética e complexamente, as culturas e as políticas.

Quanto à dimensão de políticas, diferente do que outras áreas tendem a pensar, pensamo-las como intenções que objetivam influenciar ações e culturas. Neste sentido, 
tratam-se não apenas das conhecidas políticas públicas, promulgadas pelo poder legislativo nacional ou local, como também das chamadas políticas do 'cotidiano', aquelas que cada pessoa "promulga" para si mesma ou outrem, como por exemplo, uma promessa (a si e/ou aos outros). Políticas podem ser implementadas ou não e, tal como as dimensões anteriores, elas as influenciam, dialética e complexamente.

Convém ressaltar que estas três dimensões foram primeiramente propostas por Booth e Ainscow (2002), ainda que com sentidos levemente diferenciados dos que aqui propomos. Para os autores, as culturas seriam as bases da mudança, coisa que na Omnilética inexiste: todas as três dimensões têm o mesmo valor, por assim dizer, e se influenciam mutuamente de forma complexa e dialética, com predominância, se houver, apenas temporária, de uma para outra.

A dimensão dialética é posta na omnilética no sentido de apontar para a necessidade de uma visão totalizante dos fenômenos em jogo naquilo que se investiga. Deste modo, o autor marxista que melhor nos representa é Lukács (2010), quando discute a questão da totalidade em termos de complexos e complexos de complexos ${ }^{4}$.

Por fim, mas nem por isso menos importante, extraímos de Morin (2015) a ideia de complexidade naquilo que o pensamento complexo nos traz quanto à necessidade de não simplificarmos o conhecimento nem nossa forma de compreender o mundo e de levarmos em conta, em base contínua, o princípio da incerteza, segundo o qual sempre pode haver mais uma porta, ainda entreaberta ou escondida, a qual podemos abrir para vislumbrar novas possibilidades de análise dos fenômenos, o que pode possibilitar novas formas de soluções a problemas ${ }^{5}$.

Assim, a perspectiva omnilética, fazendo uso destas dimensões nas formas como aqui descritas, propõe que pensemos o mundo e as sociedades e seus sujeitos e habitantes a partir da maior variedade possível que nosso olhar nos permita, quando tomamos em conta culturas, políticas e práticas neste jogo simultaneamente dialético e complexo. Em assim fazendo, o mesmo fato observado pode receber vários destaques culturais, políticos e práticos a cada mirada, um podendo, sempre provisoriamente, ser mais imediatamente visível do que o outro, mas o outro sempre ressurgindo e, provisoriamente, podendo sobrepor os outros, na medida em que observamos como se entretecem dialética e complexamente.

4 Para maiores referências sobre isto ver SANTOS, M. Culturas, Políticas e Práticas de Inclusão na Administração Pública: Contribuições a Partir de Uma Escola de Governo (2017).

${ }^{5}$ Para uma melhor compreensão do pensamento complexo e seus princípios, ver MORIN, E. Introdução ao pensamento complexo. $4^{\mathrm{a}}$. Ed. Porto Alegre: Sulina, 2015. 
Por exemplo, se estamos observando um fenômeno como a discriminação na instituição educacional e presenciamos, na cena de uma sala de aula em uma universidade, o professor comentar, em referência a um/a aluno/a com deficiência, que ele/a "não deveria estar ali”, precisamos pensar no contexto em que isto acontece, o momento, a história e trajetória deste profissional naquela instituição e em sua vida, a relação que manteve com o/a aluno/a desde o início, o quanto lhe conhece, sua formação como professor, a Unidade em que está inserido e seus valores e tradições acadêmicas, suas práticas como professor em relação aos outros/as alunos/as, e como tudo isto 'fervilha' no momento da enunciação discriminatória. Não para justificar atos injustificáveis. Mas para compreender o contexto e avaliar-se as possibilidades de transformá-lo.

Feita esta breve digressão para explicarmos conceitualmente nossa perspectiva, voltemos ao foco do texto para pensarmos, por meio dela, as duas legislações juntas e discutirmos os impactos da primeira lei na segunda e desta(s) no cotidiano de uma instituição de ensino superior, a UFRJ, com particular ênfase no tocante à formação docente.

Demonstramos na seção anterior os 7 momentos em que a temática da educação superior parece na PNEEPEI e, como mencionado, o texto da legislação em questão refere-se, primeiramente, ao ensino superior a partir da previsão de uma formação docente que contemple conhecimentos sobre as especificidades dos alunos com necessidades educacionais especiais. Isso significa dizer que a política em questão orienta a formação e, portanto, a organização curricular (o que enxergamos como uma alteração das culturas, políticas e práticas adotadas nas instituições de ensino superior) nos variados cursos de licenciaturas, o que já vem ocorrendo no âmbito da UFRJ.

No entanto, em termos de uma estruturação específica para atender aos cotistas com deficiências e transtorno do espectro autista, em que pese haver iniciativas espalhadas de grupos e laboratórios de pesquisa e extensão da e na UFRJ há muitas décadas e algumas tentativas de se unificar estas ações, foi somente em 2016 que passos mais concretos foram dados nesta direção, com a criação do Fórum Permanente UFRJ Acessível e Inclusiva (FPAI), em setembro deste ano, e a criação pouco depois e parcialmente decorrente da luta deste Fórum, da DIRAC (Diretoria de Acessibilidade), em fevereiro de 2018.

$\mathrm{Na}$ lente Omnilética, este fato nos faz ver que não houvera uma preocupação "concreta" com o preparo dos docentes já atuantes no ensino superior que, por sua vez, 
também atuam passaram a ter que atuar com o público alvo da educação especial, a partir do segundo semestre letivo de 2017, quando da promulgação da Lei $\mathrm{n}^{\circ}$ $13.409 / 2016$.

Não é que não houvesse alunos com deficiência na UFRJ antes das cotas. Eles sempre estiveram por lá. Mas não eram visíveis e eram deixados aos professores mais "pacientes", por assim dizer, pelo que se pode supor. A Lei de Cotas trouxe modificações estruturais neste sentido, por ter aumentado este público estudantil em número, por ter obrigado as universidades a lhes receberem e atenderem e, como consequência, por ter feito com que eles fossem, inevitavelmente, a partir de então, da responsabilidade de todo e qualquer professor/a em cujas disciplinas tais alunos se inscrevessem. deste modo, os "impacientes" foram e têm sido forçados a reverem suas posturas, um movimento que, dialético como é, impactou as culturas e práticas anteriormente "tradicionalizadas" no sentido de se revisarem.

Em 2018, por exemplo, a UFRJ teve 128 matrículas de alunos com deficiências deferidas em diferentes cursos de graduação, o que impactou o cotidiano dos Centros e Institutos que receberam esses novos estudantes. Foram e continuam sendo muitos os desafios institucionais para o atendimento adequado a esse público. Vemos falas das mais variadas a este respeito, desde aquelas que afirmam que "estes alunos não deveriam estar aqui [na universidade]" àquelas que se preocupam em inovar o ensino, rever o currículo e aprender com este alunado, antes invisibilizado, e agora, compulsoriamente visível.

Por outro lado, como dito acima, algumas ações já foram implementadas. A criação da Diretoria de Acessibilidade (DIRAC), no início de 2018, vinculada ao Gabinete do Reitor, é a principal delas, pois tem por objetivo orientar as Unidades e Decanias, apoiar o desenvolvimento de projetos e ações e, em alguns casos, acompanhar casos específicos, além de construir a política de acessibilidade da Universidade e tentar realizar um trabalho de reeducação de toda a comunidade universitária no que tange à temática do atendimento aos alunos com deficiências. Por fim, também é sua função a construção de uma base de dados para acompanhamento desses estudantes.

Em um segundo momento, o texto da PNEEPEI cita o Plano Nacional de Educação em Direitos Humanos de 2006, que teve em um de seus itens a objetivação de “desenvolver ações afirmativas que possibilitem acesso e permanência na educação superior", o que dialoga estreitamente com a lei $\mathrm{n}^{\mathrm{o}}$ 13.409/2016. No caso da UFRJ, o que se tem pensado, via DIRAC e FPAI, a este respeito, é a construção de uma 
disciplina genérica, para todos os cursos, sobre acessibilidade, assim como formas de se instigar que cada unidade reveja seu currículo para inserir a discussão na formação de nossos alunos.

No nível da pós-graduação, foi instituído em 2017 um Edital que premia ações afirmativas na pós, e que tem tido uma grande procura por variados grupos de pesquisa e docentes. A Pró-reitoria de pessoal também tem incentivado iniciativas de formação dos servidores na temática da acessibilidade, e desde 2017 temos visto a ampliação de cursos de extensão e especialização voltados para a temática. Talvez a principal ação esteja sendo a atual construção da política de acessibilidade da instituição, que terá como objetivo orientar e promover formas de coordenação de todas estas (e outras) iniciativas, incluindo a construção futura dos editais de acesso via ENEM/SISU.

A questão da permanência retorna à cena no terceiro dos sete momentos em que a PNEEPEI trata da educação superior, quando sinaliza o eixo de ação do Plano de Desenvolvimento da Educação (2007) que trata da permanência das pessoas com deficiência nessa etapa educacional.

Há, portanto, uma nítida intenção nas duas políticas públicas em debate sobre a permanência dos estudantes com deficiências nas universidades federais, apesar de não orientar especificamente as práticas a serem adotadas nesse sentido. Deste modo, fica a cargo das instituições de ensino superior a assimilação e efetivação (dimensões cultural, política e prática) desse processo. Dialeticamente, na UFRJ, a preocupação com a permanência tem se dado de maneira clara (cultural, política e praticamente falando), ainda que repleta de dificuldades orçamentárias e de pessoal.

Um olhar Omnilético sobre os dados nos traz alguns desdobramentos ocorridos até o presente momento, como a adaptação de material didático e de provas e a instalação de tecnologias assistivas (impressora Braille e softwares). No entanto, esses desdobramentos ainda representam complexidades parciais dentro da complexidade (no sentido moriniano do termo) com o que o tema da permanência dos estudantes com deficiências na universidade vem se mostrando.

Assim sendo, alguns desafios ainda se apresentam para a reconfiguração de algumas culturas, políticas e práticas que visam garantir a permanência (isso porque o acesso já está garantido) dos alunos e alunas com deficiências nos diferentes campus da Universidade, como: a construção de um banco de dados com informações sobre quem é e onde está esse público, a construção de uma política de acessibilidade para a instituição e o atendimento às necessidades de acessibilidade (todas: arquitetônica, 
atitudinal, de comunicação e informação, de transporte intra campus) em toda a UFRJ, e muitas outras que ainda nem foram identificadas.

Outra seção da PNEEPEI trata do diagnóstico da educação especial e faz referência aos dados do Censo da Educação Especial no Ensino Superior. O que vimos ocorrer na UFRJ até a implantação da lei no 13.409/2016 foi um não controle dos dados desses estudantes. Foi apenas com a criação e efetivação da DIRAC, ainda que em tão pouco tempo, que o acompanhamento desses graduandos começou a ser realizado e sistematizado. Mas mesmo esta ação ainda carece de organização e crescimento. Um dos obstáculos que temos encontrado nesta direção é a articulação com outros setores da universidade com quem é necessário planejar e trabalhar juntos, como por exemplo, a Pró-reitoria de graduação, que organiza o acesso e as matrículas, entre outras importantes funções. Dado o tamanho da UFRJ, por vezes, esta articulação fica bastante prejudicada e isto tem se mostrado um importante desafio a ser superado.

De todo modo, estes aspectos apontam para os desejos e intenções da Universidade e também para as ações que estão sendo executadas e as que estão sendo planejadas. Ao reconhecer a necessidade de acompanhar esses estudantes para, a partir disso, conhecer o todo e pensar em ações que atendam às demandas desse todo, reconhecemos a presença de uma busca pela totalidade que compõe o fenômeno da inclusão dentro da UFRJ.

A seção dedicada ao objetivo da PNEEPEI, por sua vez, visa garantir a transversalidade da educação especial:

Na educação superior, a transversalidade da educação especial se efetiva por meio de ações que promovam o acesso, a permanência e a participação dos alunos. Estas ações envolvem o planejamento e a organização de recursos e serviços para a promoção da acessibilidade arquitetônica, nas comunicações, nos sistemas de informação, nos materiais didáticos e pedagógicos, que devem ser disponibilizados nos processos seletivos e no desenvolvimento de todas as atividades que envolvem o ensino, a pesquisa e a extensão (BRASIL, 2008, p. 17).

Essa transversalidade, que não é abordada na lei $n^{\circ} 13.409 / 2016$, porque dispõe apenas sobre a reserva de vagas para pessoas com deficiência nos cursos técnicos de nível médio e superior das instituições federais de ensino, perpassa os demais momentos já explicitados e analisados, sobretudo na delimitação que escolhemos para este artigo, a UFRJ. 
O mesmo acontece com o penúltimo momento em que o texto da PNEEPEI refere-se ao ensino superior, apontando para a necessidade de ações que promovam, além do acesso e da permanência já explorados, a participação dos estudantes.

O pensar omnileticamente aqui nos instiga a pensar que essas ações envolvem diretamente culturas, políticas e práticas institucionais que estão sendo vistas e revistas em um contexto que tem se mostrado repleto de contradições (portanto, dialético) e ao mesmo tempo com infinitas frentes que precisam ser identificadas e atuadas (portanto, complexos). Há um desejo (cultura), uma intenção (política) e práticas voltadas para a transversalidade da educação especial e para a participação efetiva desses graduandos nas atividades acadêmicas da UFRJ, porém há contrassensos (em virtude das múltiplas relações que se estabelecem no contexto em questão como, por exemplo, gestão, corpo docente, técnicos administrativos e Estado) e demandas que atravessam esse processo (como verba e o número insuficiente de servidores).

Por fim, em um movimento que enxergamos como omnilético, a PNEEPEI aponta a necessidade de formação para os docentes na área da educação especial, o que lhes permitirá uma atuação nos núcleos de acessibilidade das instituições de ensino superior. Esse é um desafio para o cotidiano da UFRJ e que ainda não foi implementado, como vimos anteriormente.

Por outro lado, como também já mencionado, existe uma previsão já sinalizada pela DIRAC de algumas práticas que visam a reflexão e a (re)construção de culturas e políticas que dialogam com essa orientação de formação docente no âmbito da universidade em questão como: a criação de uma disciplina com a temática de acessibilidade, o apoio e a participação em eventos envolvendo a temática de acessibilidade, o que inclui o $1^{\circ}$ Festival UFRJ de Acessibilidade com previsão para novembro de 2018. No entanto, partindo de um olhar omnilético, previsão não é garantia de efetivação e, ainda que estando repleta de boas intenções, a Universidade é cotidianamente afetada por questões imprevisíveis e, por vezes, contraditórias, sobretudo aquelas relacionadas ao momento político, nada favorável aos setores públicos, que a sociedade brasileira atravessa.

\section{Considerações finais}

Procuramos, no decorrer deste artigo, refletir sobre três grandes questões a partir de nossa experiência com a UFRJ: Que impactos podemos dizer que a PNEEPEI trouxe 
ao cotidiano universitário? Que desafios decorreram desta política? O que foi implementado e o que não foi?

Vimos que os impactos foram profundos, tanto no sentido de inspirar os trabalhos de grupos e laboratórios que já trabalhavam com a causa e de mobilizá-los a provocar mudanças na universidade, quanto no sentido de constituir um contexto legislativo que, eventualmente, contribuiu para a promulgação da Lei 13.409/16, que mais impactou e tem impactado o cotidiano das universidades.

Se vemos este movimento de forma muito positiva, não podemos, por outro lado, deixar de reconhecer, em resposta à nossa segunda questão norteadora, que os desafios que se impuseram têm sido numerosos, sendo o principal deles, em nosso ver, a promoção de uma mudança de mentalidade (culturas) em nossa comunidade, e em particular, nos docentes que ainda resistem, pois consideramos este segmento da universidade a mola-mestra que permitirá uma efetiva revolução em direção à tão sonhada inclusão e acessibilidade de nossa população com deficiência, seja ela composta de alunos, docentes ou técnico-administrativos.

Ainda assim, pudemos mostrar, em resposta à terceira questão, o quanto tem sido feito, o quanto se está tentando fazer, mas, acima de tudo, o tanto que ainda teremos que levar a cabo. Isto não nos assusta, pelo contrário! Em um olhar omnilético, estamos acostumados a entender que cada desafio abre novas possibilidades de modificação de culturas, políticas e práticas em jogo, modificações estas que, por sua vez, trarão novos desafios e, com eles, mais possibilidades de avanço. Afinal, cremos que inclusão e acessibilidade têm muito a ver com o trecho da conhecida música de Lulu Santos (1994):

\author{
Ainda vai levar um tempo \\ Pra fechar o que feriu por dentro \\ Natural que seja assim \\ Tanto pra você quanto pra mim \\ Ainda leva uma cara \\ Pra gente poder dar risada \\ Assim caminha a humanidade \\ Com passos de formiga \\ E sem, sem vontade \\ Não vou dizer que foi ruim \\ Também não foi tão bom assim...
}

AGRADECIMENTOS: CNPq e CAPES. 


\section{REFERÊNCIAS}

BOOTH, T; AINSCOW, M. Index para a Inclusão: desenvolvendo a aprendizagem e a participação na escola. 2 ed. UNESCO/CSIE. Tradução: Mônica Pereira dos Santos. 2002.

BRASIL. Resolução CNE/CEB 1/2002 - Institui Diretrizes Curriculares Nacionais para a Formação de Professores da Educação Básica, em nível superior, curso de licenciatura, de graduação plena. MEC: Brasília - DF, 2002.

BRASIL. Plano Nacional de Educação em Direitos Humanos. MEC: Brasília, 2006.

BRASIL. Plano de Desenvolvimento da Educação: razões, princípios e programas. MEC: Brasília, 2007.

BRASIL. Ministério da Educação. Secretaria de Educação Especial. Política Nacional de Educação Especial na Perspectiva da Educação Inclusiva. Brasília: MEC/SEESP, 2008.

BRASIL. Decreto no 6.949 de 25 de agosto de 2009a. Promulga a Convenção Internacional sobre os Direitos das Pessoas com Deficiência e seu Protocolo Facultativo, assinados em Nova York, em 30 de março de 2007. Disponível em: http://www.planalto.gov.br/ccivil_03/_ato2007-2010/2009/decreto/d6949.htm. Acesso em: 08 set. 2018.

BRASIL. Decreto No 7.037 de 21 de dezembro de 2009. Programa Nacional de Direitos Humanos (PNDH3). Diário Oficial da União, Brasília, DF, 2009 b.

BRASIL. Lei 13.409, de 28 de dezembro de 2016, Altera a Lei n. 12.711, de 29 de agosto de 2012. Dispõe sobre a reserva de vagas para pessoas com deficiência nos cursos técnico de nível médio e superior das instituições federais de ensino. Disponível em: http://www.planalto.gov.br/ccivil_03/_ato2011-2014/2012/lei/112711.htm. Acesso em: 08 set. 2018.

BRASIL. Ministério da Educação. INEP/DEED. Resumo Técnico Censo Da Educação Superior 2015. INEP: Brasília, 2018. 2 ed.

CABRAL, L. S. A. Inclusão do público-alvo da Educação Especial no Ensino Superior brasileiro: histórico, políticas e práticas/Inclusion of Special Education's target audience in Brazilian Higher Education: History, policies and practices. Revista de Educação PUC-Campinas, v. 22, n. 3, p. 371-387, 2017.

LUKÁCS, G. Prolegômenos para uma ontologia do ser social: questões de princípios para uma ontologia hoje tornada possível. Tradução de Lya Luft e Rodnei Nascimento - supervisão editorial de Ester Vaisman. - São Paulo: Boitempo, 2010.

MORIN, E. Introdução ao pensamento complexo. 4 ed. Porto Alegre: Sulina, 2015. 
SANTANA, A. P. O. et al. Acessibilidade e permanência: um estudo do programa institucional de apoio aos estudantes da Universidade Federal de Santa Catarina. evista Ibero-Americana de Estudos em Educação, v. 10, p. 673-689, 2015. (Especial).

SANTOS, L. Assim caminha a humanidade. São Paulo: BMG Ariola: 1994. Suporte Marcello "Memê" Mansur.

SANTOS, M. Culturas, políticas e práticas de inclusão na administração pública: contribuições a partir de uma escola de governo. Rio de Janeiro, 2017.

SANTOS, M. P. dos. Dialogando sobre inclusão em educação: contando casos (e descasos). 1 ed. Curitiba, PR: CRV, 2013.

SIQUEIRA, I. M.; SANTANA, C. S. Propostas de acessibilidade para a inclusão de pessoas com deficiências no ensino superior. Revista Brasileira de Educação Especial, v. 16, n. 1, p. 127-136, 2010.

\section{Como referenciar este artigo}

PEREIRA DOS SANTOS, M.; BARREIROS DE LIMA, C.; SALVINO NUNES DE ALMEIDA, M. Inclusão no Ensino Superior pela Lente Omnilética: Um foco na formação docente. Revista on line de Política e Gestão Educacional, Araraquara, v. 22, n. esp. 2, p. 825-839, dez., 2018. ISSN: 1519-9029. DOI: 10.22633/rpge.unesp.v22.nesp2.dez.2018.11915

Submetido em: 25/09/2018

Aprovado em: 30/10/2018 